\title{
RELIABILITY OF NITROGEN CONTENT (\%N) AND CARBON:NITROGEN ATOMIC RATIOS (C:N) AS INDICATORS OF COLLAGEN PRESERVATION SUITABLE FOR RADIOCARBON DATING
}

\author{
Fiona Brock ${ }^{1,2} \cdot$ Rachel Wood $^{1,3} \cdot$ Thomas F G Higham $^{1}$ - Peter Ditchfield ${ }^{1}$ Alex Bayliss $^{4} \bullet$ \\ Christopher Bronk Ramsey ${ }^{1}$
}

\begin{abstract}
A recent study into prescreening techniques to identify bones suitable for radiocarbon dating from sites known for poor or variable preservation (Brock et al. 2007, 2010a) found that the percent nitrogen $(\% \mathrm{~N})$ content of whole bone powder was the most reliable indicator of collagen preservation. Measurement of $\% \mathrm{~N}$ is rapid, requires little preparation or material, and is relatively cheap. The technique reduces the risk of needlessly sampling valuable archaeological objects, as well as saving time and money on their unsuccessful pretreatment prior to dating. This method of prescreening is now regularly used at the Oxford Radiocarbon Accelerator Unit (ORAU). In the original study, linear regression analysis of data from 100 bones from 12 Holocene sites across southern England showed that when $0.76 \% \mathrm{~N}$ was chosen as a threshold, $84 \%$ of bones were successfully identified as containing sufficient (i.e. $>1 \%$ ) or insufficient (i.e. $<1 \%$ ) collagen for dating. However, it has been observed that for older, Pleistocene bones the failure rate may be higher, possibly due to the presence of more degraded, shortchain proteins that pass through the ultrafilters used in pretreatment, resulting in lower yields. Here, we present linear regression analysis of data from nearly 600 human and animal bones, antlers, and teeth, from a wide range of contexts and ages, to determine whether the $0.76 \%$ threshold identified in the previous study is still applicable. The potential of carbon:nitrogen atomic weight ratios $(\mathrm{C}: \mathrm{N})$ of whole bone to predict collagen preservation is also discussed.
\end{abstract}

\section{INTRODUCTION}

Recently, we published the results of a study seeking to find one or more criteria that could be used to prescreen bones from sites known to have poor or variable collagen preservation and to identify those samples suitable for radiocarbon dating (Brock et al. 2007, 2010a). ${ }^{14} \mathrm{C}$ dating is a costly and time-consuming process, and prescreening to identify which samples contain sufficient collagen for dating (i.e. $>1 \%$ weight yield at ORAU: van Klinken 1999) can not only save time and money, but can also prevent the unnecessary destruction of samples that are ultimately shown to be unsuitable for dating. The study analyzed nearly 300 Holocene human and animal bones from gravel sites in southern England and found that the most successful method of predicting which samples would be suitable for dating was measurement of the percent nitrogen $(\% \mathrm{~N})$ content of whole (raw) bone. Linear regression analysis of data from 100 samples demonstrated that a threshold of $0.76 \% \mathrm{~N}$ gave an $84 \%$ chance of successfully predicting whether or not a bone would contain sufficient collagen for dating.

Fresh modern bone contains $\sim 3.5-4.5 \%$ nitrogen (Stafford et al. 1988), of which $\sim 90 \%$ is present as collagen and the remaining $10 \%$ as non-collagenous proteins (NCP) (Sillen and Parkington 1996). However, the \%N content of whole bone powder cannot distinguish between nitrogen present as collagen and NCP, or that which is present from soil, e.g. proteins, nitrates, or humic acids (which have been reported to contain up to 7\% nitrogen: Yonebayashi and Hattori 1988). Likewise, nitrogen may be present within conservation treatments such as Paraloid B72. It should also be noted that measurement of $\% \mathrm{~N}$ content cannot specify the amount of non-nitrogenous soil-derived organic matter present in a specimen (Hedges and van Klinken 1992). Hence, predicting the collagen content of some bones that are highly contaminated and/or degraded will always be problematic.

'Oxford Radiocarbon Accelerator Unit, Research Laboratory for Archaeology \& The History of Art, University of Oxford, Dyson Perrins Building, South Parks Road, Oxford OX1 3QY, United Kingdom.

${ }^{2}$ Corresponding author. Email: fiona.brock@rlaha.ox.ac.uk.

${ }^{3}$ Research School of Earth Sciences, The Australian National University, ACT 0200, Australia.

${ }^{4}$ English Heritage, 1 Waterhouse Square, 138-142 Holborn St., London EC1N 2ST, United Kingdom.

(C) 2012 by the Arizona Board of Regents on behalf of the University of Arizona

Proceedings of the 6th International Radiocarbon and Archaeology Symposium, edited by E Boaretto and N R Rebollo Franco RADIOCARBON, Vol 54, Nr 3-4, 2012, p 879-886 
The carbon:nitrogen atomic weight ratio $(\mathrm{C}: \mathrm{N})$ of whole bone can also provide an indication of the general state of preservation of collagen, the extent to which deamination has taken place, and/or the extent of contamination by exogeneous carbon-containing compounds such as humic acids (Tisnérat-Laborde et al. 2003). Tisnérat-Laborde et al. (2003) proposed that a $\mathrm{C}: \mathrm{N}$ ratio of $>5$ demonstrated extensive diagenesis and/or the presence of a high proportion of humic substances. Our original study of English Holocene bones generally found that those with a $\mathrm{C}: \mathrm{N}$ ratio greater than $\sim 6.5-$ 7.0 were not suitable for dating (Brock et al. 2007), but Kim et al. (2011) found that Korean archaeological samples with $\mathrm{C}: \mathrm{N}$ ratios of up to 11 could successfully yield sufficient collagen for dating.

Measurement of both $\% \mathrm{~N}$ and $\mathrm{C}: \mathrm{N}$ ratio is relatively quick and inexpensive: it requires only $\sim 5 \mathrm{mg}$ of sample and little preparation. At ORAU, following discussion with the sample submitters, we measure the $\% \mathrm{~N}$ content of bone samples when needed to aid selection of samples suitable for dating from sites known or suspected to have poor or variable collagen preservation, or to justify the destructive analysis of samples of special significance. However, as already mentioned, our original study was of Holocene bones from England, and $\% \mathrm{~N}$ screening appeared to be less successful in predicting the outcome of older, Pleistocene bones. Here, we present analysis of $\% \mathrm{~N}$ data from 586 human and animal bones, teeth, and antlers (including those from the original study) from a wide range of contexts ranging in age from Paleolithic to Bronze Age from around the world. We also present the corresponding $\mathrm{C}: \mathrm{N}$ ratio data for over 300 of these samples.

\section{METHODS}

Bones were initially surface cleaned to remove contaminants, usually by air abrasion with fine aluminium oxide powder, and then a small amount of bone powder $(5-10 \mathrm{mg})$ was drilled using a tungsten carbide spherical burr drill bit (Brock et al. 2010a). Dentine was targeted when sampling teeth. Where air abrasion was not possible (e.g. when sampling in museums or on site), the surface bone material was drilled and discarded before material was collected for analysis. About $5 \mathrm{mg}$ of bone powder was weighed into clean tin capsules and the $\% \mathrm{~N}$ and $\% \mathrm{C}$ contents and $\mathrm{C}: \mathrm{N}$ ratio were measured using an automated carbon and nitrogen elemental analyzer (Carlo Erba EA1108). Reproducibility is $0.1 \%$ at $1 \sigma$ for samples weighing $>2 \mathrm{mg}$.

Bones that were identified for ${ }^{14} \mathrm{C}$ dating were then drilled at the same spot as the initial sample was taken from to avoid issues caused by variability in preservation within the specimen. When sampling teeth, dentine is drilled, although it is rarely possible to exclude the inclusion of small amounts of enamel when large samples are taken. The samples were subjected to ORAU's routine bone pretreatment process, which includes ultrafiltration using a $30-\mathrm{kD}$ ultrafilter, as described by Bronk Ramsey et al. (2004) and Brock et al. (2010b). The resultant collagen was weighed and the \% wt collagen yield calculated as a percentage of the starting weight of bone powder used prior to AMS ${ }^{14} \mathrm{C}$ dating. Samples that yield $<1 \%$ wt collagen are not routinely dated at ORAU (van Klinken 1999), nor are those yielding $<10 \mathrm{mg}$ collagen (Wood et al. 2010). (However, it should be noted that ultrafiltration tends to result in good quality extracted collagen, and under certain circumstances samples that have yielded $<1 \%$ wt collagen are occasionally deemed adequate for dating; these samples are then issued with OxA-X-, rather than OxA-, numbers.)

Linear regression analysis of data from 586 bones, antlers, and teeth was used to calculate the percentage of nitrogen in whole bone powder required to produce $1 \% \mathrm{wt}$ collagen using the equation:

$$
\text { Cpred }=a+b N
$$

where $C=\%$ wt collagen and $N=\%$ nitrogen content of whole bone. 
We also investigated:

i) the data from bones only (i.e. excluding antlers and teeth);

ii) the $\% \mathrm{~N}$ threshold for less well-preserved bones, i.e. those older than $25 \mathrm{ka}$ (note that for bones that yielded $<1 \%$ wt collagen and were therefore not dated, the age had to be assumed based on the archaeological information available);

iii) whether any site-specific trends were observed;

iv) whether $\mathrm{C}: \mathrm{N}$ ratio could be used as an alternative to $\% \mathrm{~N}$ to predict whether a bone would yield $>1 \%$ collagen.

\section{RESULTS AND DISCUSSION}

The results of the linear regression analysis for $\% \mathrm{~N}$ measurement are given in Table 1 . The analysis suggests that a general threshold of $\sim 0.7 \% \mathrm{~N}$ can still be applied when prescreening bones, antlers, and teeth, but that the chance of successfully predicting the outcome of collagen extraction is $72 \%$ (Table 1). When antlers and teeth are removed from the data set, the success prediction rate increases slightly from $72 \%$ to $73 \%$ (although the threshold is unchanged), still lower than the $84 \%$ observed in the original study (Brock et al. 2007, 2010a). Although the total number of antlers and teeth in the starting data set was small $(n=49)$, teeth are notably difficult to sample and $\% \mathrm{~N}$ measurements may have been carried out on samples containing a mixture of enamel and dentine.

Table $1 \% \mathrm{~N}$ cut-off values required to yield $1 \%$ wt collagen or more as predicted by linear regression analysis, and the associated prediction success rate for each $\% \mathrm{~N}$ threshold value.

\begin{tabular}{llll}
\hline Data set & $\begin{array}{l}\text { Nr of samples } \\
(n)\end{array}$ & $\begin{array}{l}\% \mathrm{~N} \\
\text { threshold }\end{array}$ & $\begin{array}{l}\text { \% prediction } \\
\text { success }\end{array}$ \\
\hline All samples (bones, teeth, antlers) & 586 & 0.7 & 72 \\
Bones only & 537 & 0.7 & 73 \\
Bones only, >25 ka & 153 & 0.8 & 68 \\
Bones only, Çatalhöyük & 68 & 1.1 & 79 \\
Bones only, Bondi & 17 & 1.2 & 65 \\
Original study & 100 & 0.8 & 84 \\
\hline
\end{tabular}

Figure 1 shows the number (and percentage) of bone samples that yielded $<1 \%$ and $>1 \%$ wt collagen for $0.25 \%$ ranges of $\% \mathrm{~N}$ content. No bones containing $<0.25 \% \mathrm{~N}$ yielded sufficient collagen for dating, and only $15 \%$ of those with $0.25-0.49 \% \mathrm{~N}$ did. Some $42 \%$ of the samples containing 0.50 $0.75 \% \mathrm{~N}$ (at, and just below, the $0.7 \%$ threshold identified in this study for yielding sufficient collagen for dating) yielded $1 \% \mathrm{wt}$ collagen or more, as did only $58 \%$ of the samples containing 0.75 $0.99 \% \mathrm{~N}$ (i.e. immediately above the $0.7 \%$ threshold). The chance of yielding sufficient collagen for dating increased to over $80 \%$ for samples containing at least $1.5 \% \mathrm{~N}$, but samples were only guaranteed to yield $>1 \% \mathrm{wt}$ collagen when they contained at least $3.0 \%$ nitrogen.

Figure 2 shows the scatter of the $\%$ wt collagen plotted against $\% \mathrm{~N}$ for the bones analyzed. The number of bones correctly and incorrectly "passed" for dating or "failed" (those discarded and not dated) using both thresholds of $0.5 \%$ and $0.7 \% \mathrm{~N}$ are given in Table 2 . Using $0.5 \%$ as the threshold for deciding whether or not a sample is suitable for dating is only slightly less successful than when $0.7 \%$ is used $(72 \%$ compared with $73 \%)$. Fewer samples that contained sufficient collagen for dating were incorrectly discarded when using the lower $(0.5 \%)$ threshold, but this may be an artifact of the data set (as discussed below). 


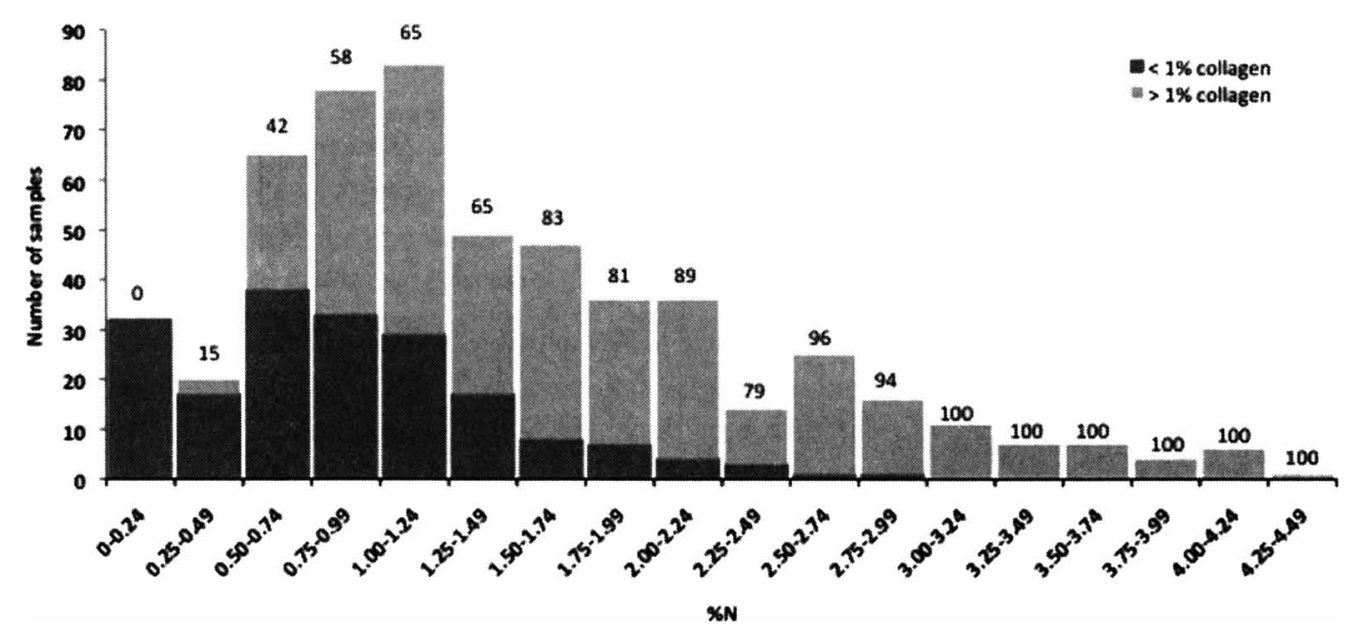

Figure 1 Number of samples that yielded $\geq 1 \%$ wt collagen and $<1 \%$ wt collagen for different ranges of $\% \mathrm{~N}$ content. The percentage of samples that yielded $>1 \%$ wt collagen for each range of $\% \mathrm{~N}$ is given above the corresponding column.

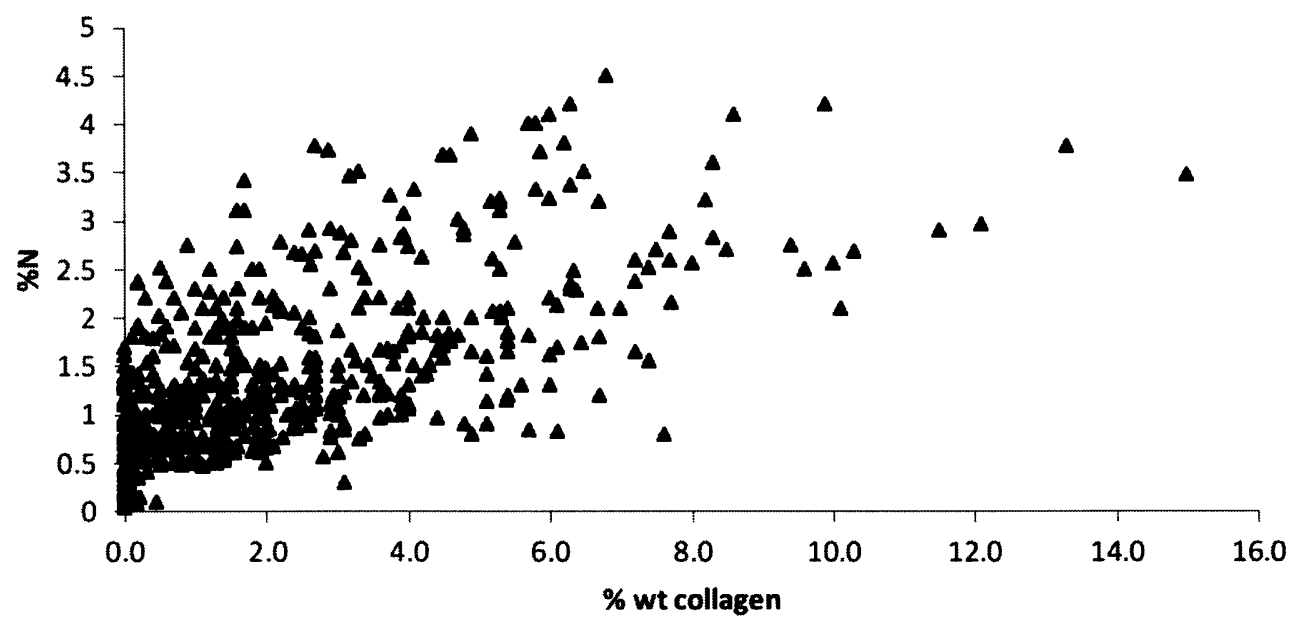

Figure 2 Scatter plot of $\%$ wt collagen versus $\% \mathrm{~N}$ of whole bone powder for 537 bones

Table 2 Percentage of samples that were correctly or incorrectly "passed" (i.e. submitted for collagen extraction for dating) of "failed" (i.e. discarded prior to dating) for several different criteria thresholds.

\begin{tabular}{lllll}
\hline Threshold & $\begin{array}{l}\text { Correctly "passed" } \\
(\%)\end{array}$ & $\begin{array}{l}\text { Incorrectly "passed" } \\
(\%)\end{array}$ & $\begin{array}{l}\text { Correctly "failed” } \\
(\%)\end{array}$ & $\begin{array}{l}\text { Incorrectly "failed" } \\
(\%)\end{array}$ \\
\hline$\% \mathrm{~N}=0.7$ & 61 & 23 & 12 & 3 \\
$\% \mathrm{~N}=0.5$ & 64 & 27 & 8 & $0^{\mathrm{a}}$ \\
$\mathrm{C}: \mathrm{N}=17.0$ & 62 & 29 & 9 & 0 \\
\hline
\end{tabular}

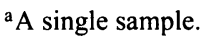


In the majority of cases where the $\% \mathrm{~N}$ failed to correctly predict whether or not sufficient collagen would be yielded, samples with high $\% \mathrm{~N}$ values yielded little or no collagen (defined as "incorrectly passed" in Table 2). This is not unsurprising, as by definition the presence of collagen will require the presence of nitrogen, although there may be a small bias in the data set as samples with only slightly less than the threshold of $0.7 \% \mathrm{~N}$ were not always pretreated but may still have yielded at least $1 \%$ collagen (see Figure 1). Where samples contained $>0.7 \% \mathrm{~N}$ but gave low yields of collagen, the nitrogen detected may have been present as short-chain, degraded collagen proteins or polypeptides that passed through the ultrafilters, or from other NCPs, contaminants from the soil or conservation treatments. The "collagen" that passed through the ultrafilters was collected and weighed for 85 of the samples analyzed in this study, and this $<30-\mathrm{kD}$ fraction was found to comprise up to $68 \%$ of the total collagen yield of the sample (with an average value of $22 \%$ ).

Older bones (i.e. those $>25 \mathrm{ka}$, either by ${ }^{14} \mathrm{C}$ dating or based on archaeological information) required $0.8 \% \mathrm{~N}$ to yield $>1 \%$ collagen, but had a lower overall prediction success rate of $68 \%$. This is probably due in part to the presence of short-chain, degraded collagen proteins that pass through the ultrafilters, although Sillen and Parkington (1996) suggest that humic acids in particular could account for residual nitrogen in older samples.

The opportunity for site-specific analysis is limited due to the small data sets available for most sites. However, where there are sufficient data for such analysis, it can be seen that the success of $\% \mathrm{~N}$ screening can be variable.

The cave of Zafarraya, found at $1000 \mathrm{~m}$ altitude in the Sierra de Alhama in Andalucia, Spain, has an important collection of cut-marked and burnt Neanderthal remains, whose age has remained controversial despite the application of several dating techniques (Barroso 2003). Twenty-nine bones from throughout the cave, thought to be Middle Paleolithic in age, were analyzed for $\% \mathrm{~N}$ content, and a total of 5 samples underwent ${ }^{14} \mathrm{C}$ pretreatment. $\% \mathrm{~N}$ analysis was useful in predicting that 3 of the bones from the front of the cave were suitable for ${ }^{14} \mathrm{C}$ dating, but that none from the back were.

The site at Çatalhöyük in central Anatolia comprises 2 distinct tells, the eastern one of which spans over $1200 \mathrm{yr}$ of Neolithic occupation. Excavations were first undertaken in the 1960s under the direction of James Mellaart (1967), and further excavations have been undertaken since 2003 under the direction of Ian Hodder (2006). Current work aims to produce a precise chronology for the entire sequence of the east mound, by ${ }^{14} \mathrm{C}$ dating up to 600 new samples (the majority of which will be articulating bone groups) and combining the resultant dates with the detailed stratigraphic sequence using Bayesian statistics (Bayliss et al., forthcoming). Based on a large suite of bone samples processed for carbon and nitrogen stable isotopes before this study began (Richards et al. 2003), it was expected that $79 \%$ of bones from Çatalhöyük would produce sufficient protein for ${ }^{14} \mathrm{C}$ dating. Potential samples have therefore been screened by measuring $\% \mathrm{~N}$ content before collagen extraction and dating to identify datable specimens. Analysis of data from the 68 samples from Çatalhöyük that have been processed at the ORAU so far shows that $1.1 \% \mathrm{~N}$ is required for bones from this site to yield $1 \%$ wt collagen (Table 1), with a $79 \%$ prediction success rate. Two of the 68 bones studied from Çatalhöyük were washed in ultrapure water prior to any pretreatment, and ion-exchange chromatography of the water rinses demonstrated the removal of nitrates from the bones. The presence of nitrates in the depositional environment at Çatalhöyük may be responsible, at least in part, for the presence of non-collagenous nitrogen, which affects the prediction success rate of $\% \mathrm{~N}$ at this site, but further investigation is still ongoing.

Similarly, collagen preservation at the Middle and Upper Paleolithic site at Bondi, Georgia, is known to be variable and, of the 17 bones prescreened that contained $0.7-1.9 \% \mathrm{~N}$, only 8 yielded 
$>1 \%$ wt collagen. Linear regression analysis of the $\% \mathrm{~N}$ and $\%$ wt collagen data of these 17 specimens indicated that to yield $1 \%$ collagen from bones at Bondi, $1.2 \% \mathrm{~N}$ is required (although the reason for this is unknown), with a prediction success rate of $65 \%$ (Table 1). This demonstrates the variation in $\% \mathrm{~N}$ content and collagen preservation between individual sites. Hence, where sufficient data becomes available for linear regression analysis of the data from an individual site to be undertaken, it can be useful to calculate and apply site-specific $\% \mathrm{~N}$ thresholds and prediction rates if further samples are to be ${ }^{14} \mathrm{C}$ dated.

$\mathrm{C}: \mathrm{N}$ atomic weight ratio data is available for 312 bone samples within the larger data set, and Figure 3 shows a scatter plot of \% wt collagen versus C:N ratio. Linear regression analysis shows that a threshold of 17.0 gave a prediction success rate of $71 \%$ (compared to a $\% \mathrm{~N}$ success rate of $76 \%$ with a threshold of $0.7 \%$ for this data set). Applying Kim et al.'s (2011) threshold of $\leq 11$ produces a slightly higher prediction success rate of $73 \%$. Figure 4 shows the number (and percentage) of bone samples that yielded $<1 \%$ and $>1 \%$ wt collagen for specific ranges of $\mathrm{C}: \mathrm{N}$ ratios.

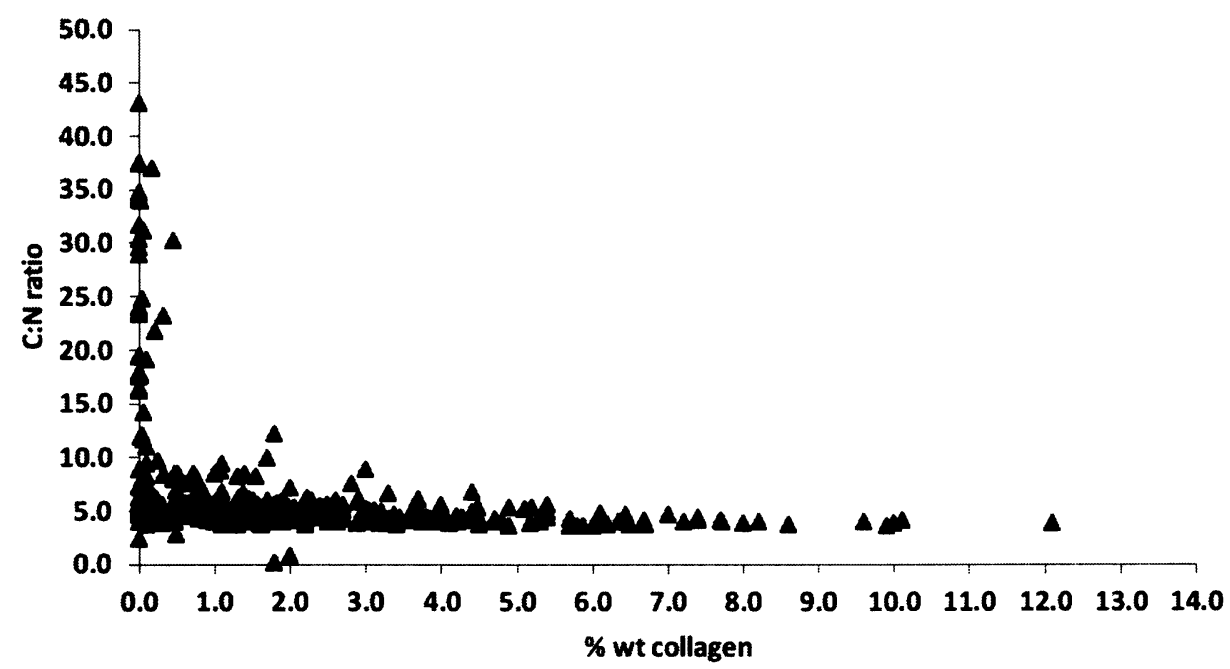

Figure 3 Scatter plot of \% wt collagen versus C:N atomic weight ratio of whole bone powder for 312 bones

Measurement of either the $\% \mathrm{~N}$ content and, to a slightly lesser extent, the $\mathrm{C}: \mathrm{N}$ ratio of whole bone powder is clearly useful for prescreening bones prior to the extraction of collagen for ${ }^{14} \mathrm{C}$ dating, but several caveats need to be considered before implementing the procedure. Firstly, bones that are not thought to be problematic (that are either considered to be well preserved or are from archaeological sites not known for poor or variable preservation) are rarely screened for $\% \mathrm{~N}$ or $\mathrm{C}: \mathrm{N}$ ratio. This means that the pattern presented here may not apply to all sites, only those with poor or variable collagen preservation. Similarly, bones with $0.5-0.7 \% \mathrm{~N}$ have often not been pretreated following the implementation of the $0.7 \%$ threshold identified in the original study (Brock et al. 2007, 2010a). A lack of collagen yield data from such samples may have influenced the prediction success rate, as well as the number of samples incorrectly "failed" (Table 2), when a threshold of $0.5 \% \mathrm{~N}$ is applied to the data set compared to a threshold of $0.7 \%$.

Secondly, while the method can be useful when selecting specimens for dating from a site where a large number of samples are available, care must be taken not to add a stratigraphic (and potentially chronological) bias by selecting only the samples with the highest $\% \mathrm{~N}$ or lowest $\mathrm{C}: \mathrm{N}$ ratio without taking the site stratigraphy into consideration. 


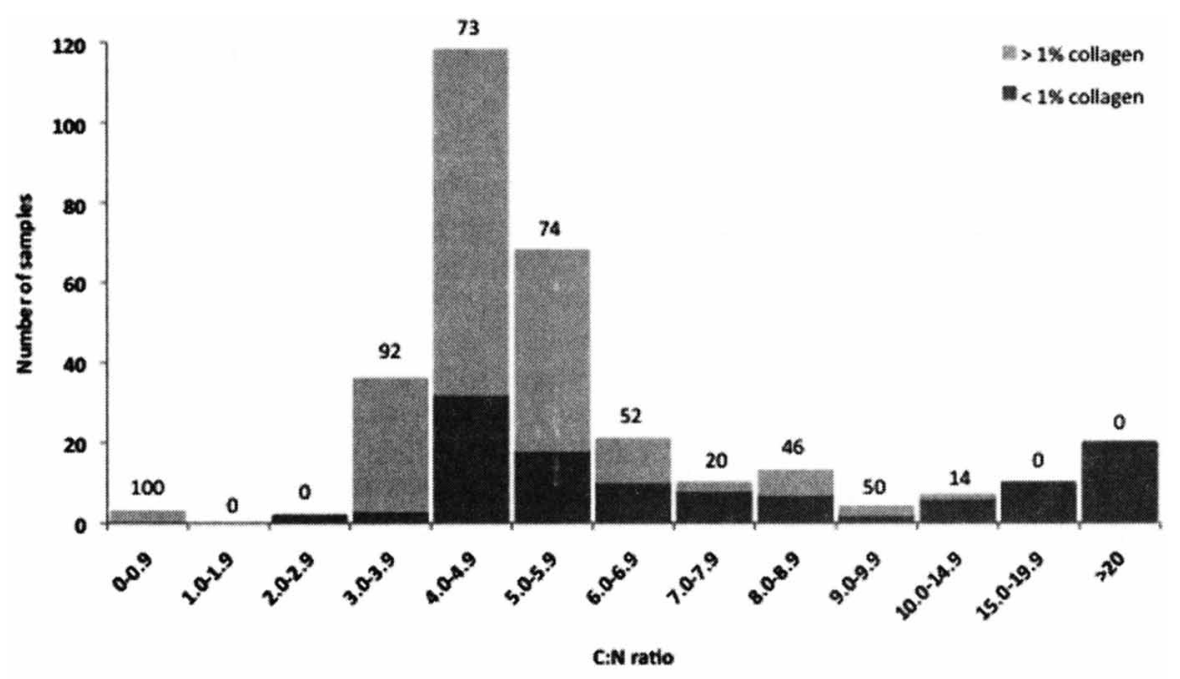

Figure 4 Number of samples that yielded $\geq 1 \%$ wt collagen and $<1 \%$ wt collagen for different ranges of $\mathrm{C}: \mathrm{N}$ ratios. The percentage of samples that yielded $>1 \%$ wt collagen for each $\mathrm{C}: \mathrm{N}$ ratio range is given above the corresponding column.

Finally, different collagen extraction procedures are known to result in varying collagen yields (e.g. Jørkov et al. 2007). Ultrafiltration is generally considered to result in lower yields than other techniques due to the loss of short-chain polypeptides through the filters that would be retained by other procedures, and different ultrafilter membranes and molecular weight cut-offs are also known to result in variable yields. The data analyzed here is specific to the pretreatment protocol implemented at ORAU (Brock et al. 2010b), which includes an ultrafiltration step using a Vivaspin ${ }^{\mathrm{TM}} 1530-\mathrm{kD}$ MWCO ultrafilter with a polyethersulfone membrane: some of the samples that yielded $<1 \%$ collagen in this study may have given much higher yields if extracted using a different technique. Hence, the specific $\% \mathrm{~N}$ and $\mathrm{C}: \mathrm{N}$ ratio threshold values and prediction success rates are not transferable to other extraction techniques, and prescreening using $\% \mathrm{~N}$ and/or $\mathrm{C}: \mathrm{N}$ ratio measurements may not be suitable for ${ }^{14} \mathrm{C}$ laboratories that do not employ a minimum collagen yield for dating.

\section{CONCLUSION}

Measuring the percent nitrogen $(\% \mathrm{~N})$ content and/or $\mathrm{C}: \mathrm{N}$ atomic weight ratio of whole bone can be a useful tool for identifying bones that are likely to yield sufficient collagen for dating (i.e. $>1 \% \mathrm{wt}$ collagen), especially when selecting specimens to date from sites known or suspected to have poor or variable preservation, or for preventing unnecessary destruction of archaeological samples that are unsuitable for dating. Using a threshold of $0.7 \% \mathrm{~N}$ gives a $73 \%$ chance of successfully predicting whether or not a bone pretreated using ORAU's routine ultrafiltration protocol will yield sufficient collagen (i.e. $\geq 1 \%$ weight collagen) for $\mathrm{AMS}{ }^{14} \mathrm{C}$ dating. A threshold of $17.0 \mathrm{C}: \mathrm{N}$ ratio gives a $71 \%$ chance of successfully predicting collagen yield. Using both $\mathrm{C}: \mathrm{N}$ ratio and $\% \mathrm{~N}$ value together makes only a marginal improvement to collagen yield prediction success.

We will continue to measure the $\% \mathrm{~N}$ of whole powder to prescreen samples submitted to the ORAU for dating, following discussion with the submitter (either at the request of the submitter, or if we have particular concerns about the preservation state of an individual sample). Although the threshold identified by the linear regression analysis is $0.7 \% \mathrm{~N}$, each sample yielding $\sim 0.5-0.7 \% \mathrm{~N}$ will be considered individually and may still be pretreated, especially if the date of the sample is particu- 
larly important, given that $42 \%$ of bones in this study that yielded such levels of $\% \mathrm{~N}$ yielded sufficient collagen to date, and that using the lower threshold of $0.5 \% \mathrm{~N}$ resulted in fewer samples being incorrectly discarded when they were actually suitable for dating. Such samples are usually treated using a higher starting weight than normal of $\sim 1 \mathrm{~g}$, which increases the possibility of yielding sufficient collagen to date. However, when screening large numbers of bones from a particular site, it is anticipated that if there are sufficient samples with $\% \mathrm{~N}$ of $0.7 \%$ or above, these would be selected for dating in preference to those with $\% \mathrm{~N}$ in the $0.5-0.7 \%$ range (assuming this does not add a stratigraphic bias).

\section{ACKNOWLEDGMENTS}

We thank the John Templeton Foundation (Grant \#13463) for funding the analyses from Çatalhöyük reported here; $\mathrm{C}$ Barroso and $\mathrm{M}$ Caparros for access to the samples from Zafarraya and permission to publish the data; R Pinhasi (University College, Cork) for allowing publication of data for the bones from Bondi; R J Parkes, E Roussel, and X Tang (University of Cardiff) for undertaking ionexchange chromatography of water rinses from the bones from Çatalhöyük; and J Southon for a constructive and helpful review of an earlier draft of this paper.

\section{REFERENCES}

Barroso C, editor. 2003. El Pleistoceno Superior de la Cueva del Boquete de Zafarraya. Sevilla: Junta de Andalucia.

Bayliss A, Farid S, Higham T. Forthcoming. Time will tell: practising Bayesian chronological modelling on the East Mound. In: Hodder I, editor. Çatalhöyük Excavations: The 2000-2008 Seasons. Los Angeles: Cotsen Institute of Archaeology.

Brock F, Higham T, Bronk Ramsey R. 2007. Radiocarbon dating bone sites recovered from gravel sites. English Heritage Research Department Report Series 30/ 2007. London: English Heritage. http:// ads.ahds.ac.uk/catalogue/archive/bigravels_eh 2007.

Brock F, Higham T, Bronk Ramsey R. 2010a. Prescreening techniques for identification of samples suitable for radiocarbon dating of poorly preserved bones. Journal of Archaeological Science 37(4):85565.

Brock F, Higham T, Ditchfield P, Bronk Ramsey C. 2010b. Current pretreatment methods for AMS radiocarbon dating at the Oxford Radiocarbon Accelerator Unit (ORAU). Radiocarbon 52(1):103-12.

Bronk Ramsey C, Higham T, Bowles A, Hedges R. 2004. Improvements to the pretreatment of bone at Oxford. Radiocarbon 46(1):155-63.

Hedges REM, van Klinken GJ. 1992. A review of current approaches in the pre-treatment of bone for radiocarbon dating by AMS. Radiocarbon 34(3):279-91.

Hodder I. 2006. The Leopard's Tale, Revealing the Mysteries of Çatalhöyük. London: Thames and Hudson.

Jørkov MLS, Heinemeier J, Lynnerup N. 2007. Evaluating bone collagen extraction methods for stable iso- tope analysis in dietary studies. Journal of Archaeological Science 34(11):1824-9.

Kim KJ, Hong W, Park JH, Woo HJ, Hodgins G, Jull AJT, Lee YJ, Kim JY. 2011. Development of radiocarbon dating method for degraded bone samples from Korean archaeological sites. Radiocarbon 53(1):129-35.

Mellaart J. 1967. Çatal Hüyük: A Neolithic Town in Anatolia. London: Thames and Hudson.

Richards MP, Pearson JA, Molleson TI, Russell N, Martin L. 2003. Stable isotope evidence of diet at Neolithic Çatalhöyük, Turkey. Journal of Archaeological Science 30(1):67-76.

Sillen A, Parkington J. 1996. Diagenesis of bones from Eland's Bay Cave. Journal of Archaeological Science 23(4):535-42.

Stafford Jr TW, Brendel K, Duhamel RC. 1988. Radiocarbon, ${ }^{13} \mathrm{C}$ and ${ }^{15} \mathrm{~N}$ analysis of fossil bone: removal of humates with XAD-2 resin Geochimica et Cosmochimica Acta 52(9):2257-67.

Tisnérat-Laborde N, Valladas H, Kaltnecker E, Arnold M. 2003. AMS radiocarbon dating of bones at LSCE. Radiocarbon 45(3):409-19.

van Klinken GJ. 1999. Bone collagen quality indicators for palaeodietary and radiocarbon measurements. Journal of Archaeological Science 26(6):687-95.

Wood RE, Bronk Ramsey C, Higham TFG. 2010. Refining background corrections for radiocarbon dating of bone collagen at ORAU. Radiocarbon 52(2):600-11.

Yonebayashi K, Hattori T. 1988. Chemical and biological studies on environmental humic acids, I: composition of elemental and functional groups of humic acids. Soil Science and Plant Nutrition 34:571-84. 